\title{
The effects of firocoxib on cautery disbudding pain and stress responses in preweaned dairy calves
}

\author{
M. L. Stock, ${ }^{\star}$ S. T. Millman, ${ }^{\star} \dagger$ L. A. Barth, $\ddagger$ N. K. Van Engen, $†$ W. H. Hsu, ${ }^{*}$ C. Wang,† R. Gehring, $\S$ \\ R. L. Parsons, $†$ and J. F. Coetzee ${ }^{1}$ \\ *Department of Biomedical Sciences, \\ †Veterinary Diagnostic and Production Animal Medicine, and \\ $\ddagger$ Veterinary Clinical Sciences, College of Veterinary Medicine, lowa State University, Ames 50010 \\ §Department of Anatomy and Physiology, College of Veterinary Medicine, Kansas State University, Manhattan 66506
}

\begin{abstract}
Perioperative analgesic effects of oral firocoxib following cautery disbudding were investigated in preweaned calves. Twenty Holstein calves approximately 4 to $6 \mathrm{wk}$ old received a single oral dose of firocoxib, a nonsteroidal antiinflammatory, at $0.5 \mathrm{mg} / \mathrm{kg}(\mathrm{n}=10)$ or placebo $(\mathrm{n}=10)$ in a randomized controlled clinical trial. Responses, including ocular temperature determined by infrared thermography, pressure algometry measuring mechanical nociception threshold, and heart rate, were evaluated at $2,4,7,8$, and $24 \mathrm{~h}$ after cornual nerve block and cautery disbudding. Blood samples were collected over $96 \mathrm{~h}$ and analyzed for plasma cortisol and substance $\mathrm{P}$ concentrations by RIA. Additionally, ex vivo prostaglandin $\mathrm{E}_{2}$ concentrations were determined over a 72-h study period using an enzyme immunoassay. Data were analyzed using a linear mixed effects model with repeated measures. An inhibition of ex vivo prostaglandin $\mathrm{E}_{2}$ synthesis was observed from 12 to 48 $\mathrm{h}$ following disbudding in calves treated with firocoxib. Cautery disbudding was associated with an increased nociception for the duration of sampling $(24 \mathrm{~h})$. During the initial 24-h period following disbudding, no difference in response between treatment groups was noted. Following $24 \mathrm{~h}$, mean cortisol concentrations diverged between the 2 study groups with placebo-treated calves having increased cortisol concentrations at approximately $48 \mathrm{~h}$ after disbudding. Furthermore, the overall integrated cortisol response as calculated as area under the effect curve tended to be reduced in firocoxib-treated calves. The prolonged effects of cautery dehorning require further investigation. Moreover, the effect of firocoxib on cortisol reduction observed in this study requires additional exploration.
\end{abstract}

Received September 19, 2014.

Accepted May 18, 2015.

${ }^{1}$ Corresponding author: hcoetzee@iastate.edu
Key words: welfare, disbudding, dehorning, nonsteroidal antiinflammatory, firocoxib

\section{INTRODUCTION}

Dehorning or disbudding cattle is a management procedure commonly performed on nearly $95 \%$ of US dairy operations (USDA, 2010). Horns or horn buds are primarily removed to accommodate production practices and prevent economic loss due to carcass bruising. Many techniques have been described, with the use of a hot iron reported to be the most commonly employed method in the United States (USDA, 2010). Although the AVMA (2012) supports methods to minimize pain and distress associated with disbudding and dehorning, methods to evaluate this response can be challenging given the need to use indirect measures to assess an affect state.

Behavioral, physiologic, and neuroendocrine changes have been reported following disbudding or dehorning (Stafford and Mellor, 2005; Stock et al., 2013). These observed and reported responses are frequently interpreted as being associated with pain and distress (McMeekan et al., 1998; Faulkner and Weary, 2000; Stewart et al., 2008; Heinrich et al., 2010). More specifically, indirect measures, such as changes in the hypothalamicpituitary-adrenal axis activation resulting in cortisol release (McMeekan et al., 1998), mechanical nociception threshold (Heinrich et al., 2010), autonomic nervous system response (Stewart et al., 2008), and behavior (Faulkner and Weary, 2000), have been previously used to assess the pain and distress associated with disbudding in calves. The concurrent evaluation of several indices may improve the assessment of pain and distress in animals due to individual response variations (Molony and Kent, 1997).

As a consequence of disbudding or dehorning, acute changes in cortisol release (McMeekan et al., 1998), local nociception (Heinrich et al., 2010), ocular temperature and heart rate (Stewart et al., 2008), and head shakes 
and ear flicks (Faulkner and Weary, 2000; Stilwell et al., 2009) are reported. Local anesthetics have been useful in mitigating these acute effects following removal of the horns or horn buds (McMeekan et. al, 1998; Stewart et al., 2008; Stilwell et al., 2009); however, these local anesthetics typically demonstrate only temporary reduction of these observed responses once the local anesthetic is no longer effective (Doherty et al., 2007; Heinrich et al., 2009; Allen et al., 2013).

Subsequent to the initial tissue damage involved with horn removal, continued cortisol and behavioral changes are observed, which may be due to inflammation-related pain (McMeekan et al., 1998; Stafford and Mellor, 2005). Behavior responses are reported to persist up to 24 to $44 \mathrm{~h}$ (Faulkner and Weary, 2000; Heinrich et al., 2010). Nonsteroidal antiinflammatory drugs (NSAID), including ketoprofen (Faulkner and Weary, 2000), meloxicam (Heinrich et al., 2009), carprofen (Stilwell et al., 2012), and flunixin (Glynn et al., 2013; Huber et al., 2013), reduce responses associated with pain and distress following dehorning or disbudding. To address both the initial and continued responses, a multimodal approach using analgesics that act both acutely and at length have been proposed (Stafford and Mellor, 2011)

Currently, no compounds are specifically approved to alleviate pain in livestock in the United States (Coetzee, 2013). Concerns of efficacy and administration frequency necessary to maintain analgesia concentrations have been discussed due to the number of analgesic drugs available in the United States with short elimination half-lives (Coetzee, 2011). Heinrich et al. (2010) demonstrated the administration of meloxicam, an NSAID with a long half-life in cattle, reduced both the acute response, which included reductions in cortisol concentrations, local sensitivity as well as the prolonged painrelated behaviors. As such, the use of an NSAID with a long half-life in calves may be the most ideal for pain management. Moreover, as feed is potentially the most practical and pain-free drug delivery method that can be applied in commercial livestock production systems, analgesics administered orally should be explored. Given the diversity of the pharmacologic properties of NSAID, continued investigation for optimal pain relief for disbudding and dehorning pain will benefit animal welfare.

Firocoxib is an NSAID of the coxib class with a prolonged elimination half-life and high oral bioavailability in calves (Stock et al., 2014). As a potential additional benefit, firocoxib is COX-1 sparing in both the horse and dog, which may reduce adverse effects (McCann et al., 2002, 2004). The objective of the current study was to measure the effects of firocoxib on pain and distress in preweaned dairy calves immediately before cautery disbudding. In addition, we assessed the neuroendo- crine, nociception, and physiologic responses observed following cautery disbudding.

\section{MATERIALS AND METHODS}

\section{Animals and Housing}

Twenty Holstein calves (11 male and 9 female), 4 to 6 wk of age (mean \pm SD: $32.9 \pm 3.9$ d), weighing $55.2 \pm 5.8 \mathrm{~kg}$ at the time of disbudding were obtained from the Iowa State University Dairy. All calves were determined healthy following a physical examination by a veterinarian and normal findings on a complete blood count and serum chemistry. The study protocol was approved by the Institutional Animal Care and Use Committee at Iowa State University (Log\#: 10-12-7443-B).

Study animals were housed in individual 3-sided closed pens $(1.82 \times 1.22 \mathrm{~m})$ bedded with straw added daily in an enclosed facility at the Iowa State University Dairy. Calves were placed in these pens at birth and remained within the pens through the entirety of the study. While in these pens, calves had minimal physical contact with other calves, although contact to neighboring calves was possible during feeding through the one open side. Three liters of pasteurized waste milk was fed twice daily for the length of the study. To control for the variation in waste milk components, both treatment groups were given milk from the same batch pasteurization. Calves were fed grain, consisting primarily of pelleted corn, oats, molasses and protein-vitamin-mineral supplement, and offered water ad libitum. Grain was added daily at 0.45 to $0.90 \mathrm{~kg}$. Daily examinations were conducted by a veterinarian, including the monitoring of milk consumption and a subjective assessment of grain and water consumption throughout the study period.

\section{Study Design}

A randomized complete block design was used for this investigation, with 10 calves enrolled in each treatment group (Figure 1). The study was conducted in 2 periods. Calves were enrolled into a treatment group during period 1 and remained in that treatment group for period 2. Period 1 was conducted 2 wk before period 2 . Disbudding only occurred during period 2. The purpose of period 1 was to obtain intravenous firocoxib concentrations in calves used in a subsequent pharmacokinetic analysis (Stock et al., 2014). In period 1, study animals were blocked by age and randomly assigned to receive either firocoxib $(0.5 \mathrm{mg} / \mathrm{kg} ; \mathrm{n}=10$, male $=7)$ or a placebo $(\mathrm{n}=10$, male $=4)$. Randomization of group assignment was mediated by a computer-generated random number (Microsoft Excel 2011, Microsoft Corp., 


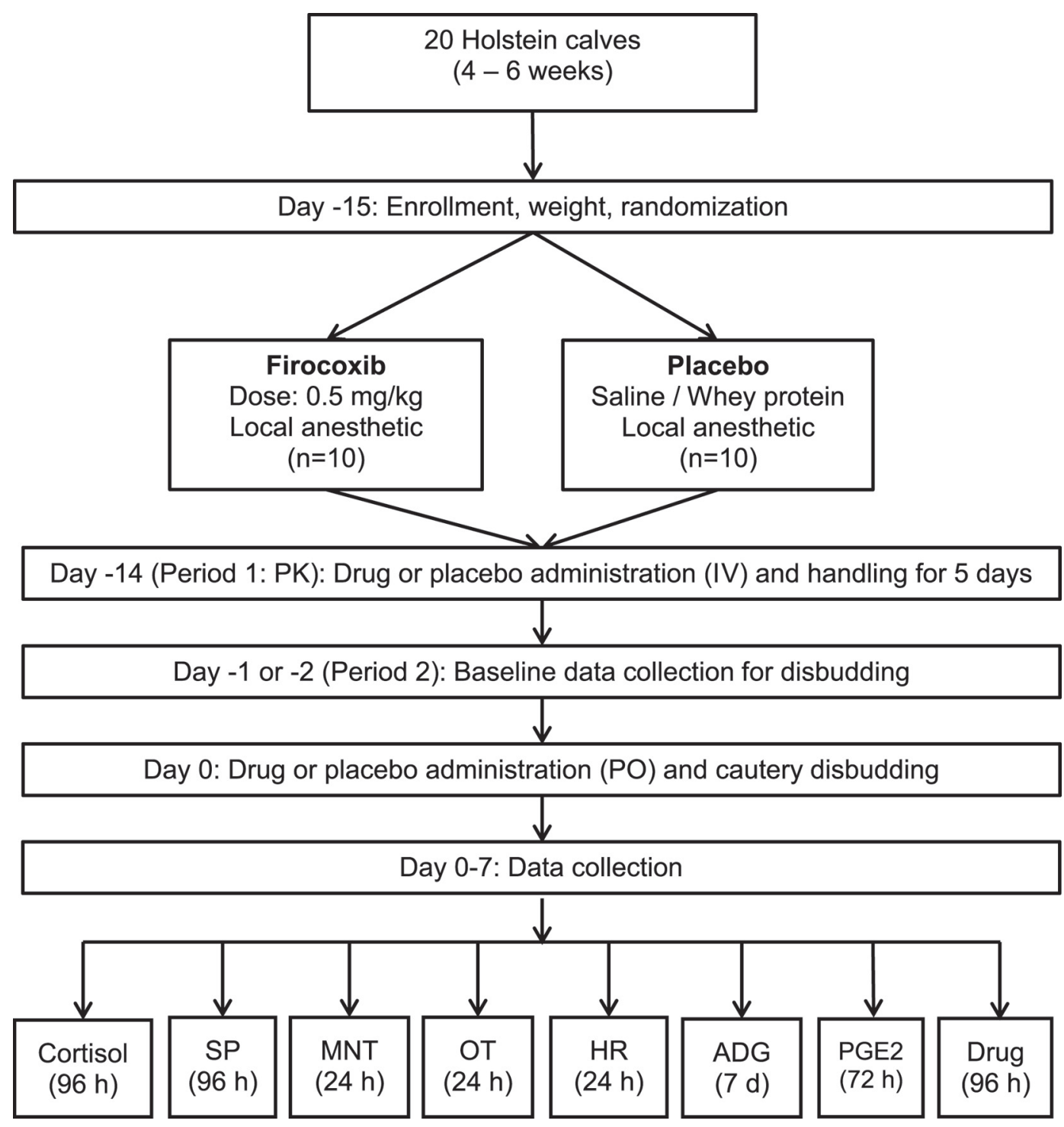

Figure 1. Flowchart outlining the timing of the study events. During period 1, firocoxib or placebo was administered intravenously to calves to provide data to be analyzed for a pharmacokinetic (PK) study. In period 2, calves were disbudded and monitored for cortisol, substance P $(\mathrm{SP})$, mechanical nociception threshold $(\mathrm{MNT})$, ocular temperature $(\mathrm{OT})$, heart rate $(\mathrm{HR}), \mathrm{ADG}$, ex vivo prostaglandin $\mathrm{E}_{2}\left(\mathrm{PGE}_{2}\right)$, and firocoxib concentration following oral (PO) administration of placebo or firocoxib. The times in parentheses represent the duration of data collection for each variable.

Redmond, WA). During period 1, calves assigned to the firocoxib group received intravenous firocoxib (Equioxx Injection, NADA 141-313, Merial LLC, Duluth, GA), whereas calves in the control group received intravenous saline via a preplaced jugular catheter followed by multiple timed blood collections. As such, calves in both treatment groups were identically handled and experienced placement and maintenance of an indwelling catheter before period 2. Following a 14-d washout period from period 1 , concentrations of firocoxib were not detected at the start of period 2. Period 2 was conducted in 2 trials using 10 animals per trial which were balanced for treatment $(\mathrm{n}=5$ calves/treatment per trial). The 2 trials were initiated on consecutive days. In period 2, calves previously receiving intravenous firocoxib now received oral firocoxib (Equioxx Oral Paste, NADA 141-253, Merial LLC) and control calves received an oral whey protein placebo (Body Fortress, Bohemia, NY).

A jugular catheter was used for blood sample collection. Placement of the jugular catheter occurred approximately $12 \mathrm{~h}$ before the start of the investigation. A handler manually restrained the calves and the area over the jugular vein was clipped and surgically pre- 
pared with alternating scrubs of $70 \%$ isopropyl alcohol and povidone iodine. The catheter site was infiltrated with $2 \%$ lidocaine injection, $1 \mathrm{~mL}$ subcutaneously (Hospira Inc., Lake Forest, IL). Using sterile technique, an 18 gauge $\times 55 \mathrm{~mm}$ intravenous catheter (Surflo, Terumo Medical Corp., Somerset, NJ) was inserted into the vein and sutured to the skin using \#3 nylon suture (Ethilon, Ethicon, San Lorenzo, PR). An injection port (Hospira Inc.) was subsequently attached and disinfected with an alcohol swab before sample collection. Catheter patency was maintained by flushing with 3 $\mathrm{mL}$ of a heparin saline solution containing 3 United States Pharmacopoeial Convention units of heparin so$\operatorname{dium} / \mathrm{mL}$ of saline (Heparin Sodium Injection, Baxter Healthcare, Deerfield, IL).

Calves assigned to receive firocoxib were administered a single oral dose of $0.5 \mathrm{mg} / \mathrm{kg}$. Oral firocoxib was administered in a commercially provided dosing syringe with syringe weights obtained before and after administration to confirm the dose administered. The dose was rounded to the nearest $22.7 \mathrm{~kg}$ (50 pounds) as designated by the increments provided on the syringe. Using a concentration of $0.82 \%$ firocoxib, the actual mean dose of $0.5 \mathrm{mg} / \mathrm{kg}$ (range: $0.48-0.52 \mathrm{mg} / \mathrm{kg}$ ) was administered to the calves as an oral paste in a dosing syringe. Control animals received an equivalent amount of whey protein mixed with water to a similar consistency as the firocoxib paste and administered via a similar shaped, voided dosing syringe. To control for the influence of milk feeding on absorption, all calves were given their milk feeding immediately after disbudding, approximately $10 \mathrm{~min}$ after firocoxib or placebo administration. In relation to disbudding, this feeding time was the same for both treatment groups.

\section{Disbudding}

Disbudding was performed in 10-min intervals by a single, experienced veterinarian and the same handler to minimize variation. The disbudding order was randomized between treatment groups to control for variation in start time. Cautery disbudding was initiated 10 min following administration of the local anesthetic and oral treatment. All calves received a local anesthetic before cautery disbudding. Desensitization of the cornual tissue was provided via a cornual nerve block using 2\% lidocaine (VetOne, Boise, ID; $5 \mathrm{~mL} /$ site), as described by Stock et al. (2013). Desensitization of the cornual tissue was confirmed using behavior reactions (e.g., ear flicks, head shaking, strong escape behavior) to a needle prick 5 min after administration of the cornual nerve block. Administration of lidocaine (1-2 mL) was repeated in the same manner described above if a response was observed to the initial needle prick. Following confirmation of appropriate desensitization, calves were cautery disbudded by placement of a preheated butane hot-iron (approximately $600^{\circ} \mathrm{C}$; Express dehorner, Guilbert Express, New York, NY) on the horn tissue for approximately $10 \mathrm{~s}$.

The disbudding sites were monitored daily for signs of discharge or infection, in addition to an assessment of attitude, posture, appetite, lying time, and perioperative swelling. A rescue analgesia protocol of flunixin meglumine at $2.2 \mathrm{mg} / \mathrm{kg}$ i.v. once daily for $3 \mathrm{~d}$ was devised if obvert pain or distress was evident, such as increased lying time, head pressing, inflammation with major drainage of the disbudding site, dehydration, or inappetence.

\section{Blood Sample Collection}

Animals were restrained during blood collection by trained handlers. Prior to sample collection, blood was aspirated and flushed back through the catheter to eliminate the heparin dilution before sample collection. Baseline samples were obtained at approximately $-1.5 \mathrm{~h}$ from disbudding. Plasma drug concentration was confirmed as undetectable at this time. Additional blood samples were collected at 15 and $30 \mathrm{~min}$ and 1, 2, $4,6,8,10,12,24,48,72$, and $96 \mathrm{~h}$ (-10 min) following disbudding. Sampling time points were determined in relation to the time drug or placebo was administered. Postdisbudding cortisol and substance $\mathrm{P}$ concentrations were subsequently analyzed in relation to the time of disbudding. Samples were immediately transferred to a blood collection tube with either heparin for cortisol and drug concentration or EDTA for substance P (Vacutainer, BD Diagnostics, Franklin Lakes, NJ) and stored on ice before processing. The EDTA tubes were spiked with $1 \mathrm{~m} M$ benzamidine (Santa Cruz Biotechnology, Santa Cruz, CA) before blood collection. Blood samples were centrifuged for $15 \mathrm{~min}$ at 1,500 $\times$ $g$ at room temperature. Collected plasma was placed in cryovials and frozen at $-70^{\circ} \mathrm{C}$ until analysis.

\section{Cortisol}

Plasma cortisol samples were determined using a commercial RIA kit (Coat-A-Count Cortisol, Siemens Medical Solutions Diagnostics, Los Angeles, CA) previously used for bovine plasma (Stilwell et al., 2008; Rialland et al., 2014). Samples were assayed in duplicate with the reported concentration equaling the average cortisol concentration between duplicates. Samples were reanalyzed if subjectively large discrepancies were noted between the duplicates. The average intra- and interassay coefficients of variation were 12.8 and $13.2 \%$, respectively. Area under the effect curve was calculated 
using the linear trapezoidal rule as previously described (Glynn et al., 2013).

\section{Substance $P$}

Substance P (SP) concentrations were analyzed as described by Van Engen et al. (2014) using nonextracted plasma. Samples were assayed in duplicate with the reported concentration equaling the average $\mathrm{SP}$ concentration between duplicates. The coefficient of variation for intra-assay variability was at $7.9 \%$ and the interassay variability was calculated at $7.7 \%$.

\section{Prostaglandin $E_{2}$}

Ex vivo prostaglandin $\mathrm{E}_{2}\left(\mathbf{P G E}_{2}\right)$ synthesis inhibition was determined as described by Fraccaro et al. (2013). Blood collected from calves was placed into sterile vacuum tubes containing heparin at 4, 8, 12, 24, 48, and $72 \mathrm{~h}$. The LPS obtained from Escherichia coli 0111:B4 (Sigma-Aldrich Co., St. Louis, MO) in PBS was added at $10 \mu \mathrm{g} / \mathrm{mL}$ to the heparinized whole blood and incubated for $24 \mathrm{~h}$ at $37^{\circ} \mathrm{C}$. Baseline samples were incubated with and without LPS. At the end of incubation, all samples were centrifuged at $400 \times g$ for $10 \mathrm{~min}$ at room temperature to obtain plasma. Methanol was added to plasma in a 1:5 plasma to methanol dilution, facilitating protein precipitation. Following centrifugation at $3,000 \times g$ for 10 min using a non-temperaturecontrolled centrifuge, the supernatant was collected and stored at $-80^{\circ} \mathrm{C}$. A commercial $\mathrm{PGE}_{2}$ ELISA kit (Cayman Chemical, Ann Arbor, MI) previously described using methanol precipitated bovine plasma was used for determination of $\mathrm{PGE}_{2}$ concentration (Donalisio et al., 2013; Fraccaro et al., 2013). The coefficient of variation for intra-assay variability was at $8.9 \%$ and the interassay variability was calculated at $12.2 \%$.

\section{Nociception and Autonomic Nervous System Responses}

Calves were restrained using a modified calf-restraining device (Easy B-Z Portable Calf Restraint, Nasco, Fort Atkinson, WI) approximately $10 \mathrm{~min}$ before determination of ocular temperature (OT), heart rate (HR), and mechanical nociception threshold (MNT). Additionally, following infrared thermography imaging and HR determination, calves were blindfolded for MNT to avoid withdrawal reflex based on visual cues. Baseline samples for OT, HR, and MNT were obtained on the same day for both trials, thus 16 and $21 \mathrm{~h}$ before initiation of the first trial and 38 and $42 \mathrm{~h}$ before initiation of the second trial. Baseline data for each animal were averaged for use in statistical analysis. In addition to baseline samples, response variables were collected at approximately $2,4,7,8$, and $24 \mathrm{~h}$ postdisbudding. All individuals collecting data were blinded to calf treatment group assignment.

Infrared Thermography. A thermography camera (FLIR SC 660, FLIR Systems, Boston, MA) with a thermal sensitivity of $0.05^{\circ} \mathrm{C}, 320 \times 240$ pixel display, precision $>98 \%$, was used to quantify changes in OT. The camera was internally calibrated to ambient temperature before image collection; however, additional minute adjustments to ambient temperature and humidity were used during software processing. Images were obtained from the left side of the calf, at an approximately $45^{\circ}$ angle, and $0.5 \mathrm{~m}$ distance from the eye. Maximum temperature $\left({ }^{\circ} \mathrm{C}\right)$ within a circumferential area of the eye, including the medial posterior palpebral border of the lower eyelid and the lacrimal caruncle, was obtained as previously described (Stewart et al., 2008). Images were analyzed using FLIR Tools (v. 4.1; FLIR Systems) following collection. At each time point, 3 images were obtained and averaged for statistical analysis.

$\boldsymbol{H R}$. Heart rate was evaluated via auscultation using a stethoscope (3M, Littmann, St. Paul, MN) placed between the third and fifth intercostal space and beats were counted over a 30 -s period. The value obtained was used to calculate beats per minute.

MNT. Pain sensitivity was measured using a handheld pressure algometer (Wagner Force Ten FDX 25 Compact Digital Force Gage, Wagner Instruments, CT) around the disbudding site, as previously described with modifications (Heinrich et al., 2010; Tapper et al., 2011; Allen et al., 2013). Two landmark locations around each horn bud as well as a control landmark were used (Figure 2). The MNT was determined as the peak applied force resulting in a withdrawal response, defined as a directed movement of the head away from the applied pressure (Tapper et al., 2011). Using a rate of approximately $1.0 \mathrm{kgf} / \mathrm{s}$, the stimulus was applied perpendicular to the landmarks. A maximum force ceiling was established at $10 \mathrm{kgf}$. To prevent bias, the MNT output was not visualized by the individual operating the algometer. Moreover, the order of MNT landmarks and the calf side from which the pressure algometrist stood to apply the stimulus was randomized between each calf to control for potential effects on MNT determination. Each algometry site was assessed 3 times for each time point with the values averaged for the statistical analysis.

\section{ADG}

Animals were weighed using a Way-Pig 505 (Raytec Manufacturing, Ephrata, PA) scale $24 \mathrm{~h}$ before the 


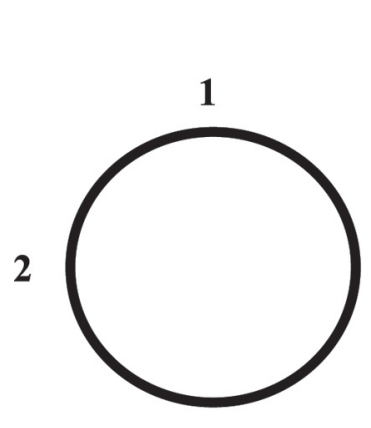

$\mathrm{L}$

\section{Caudal}

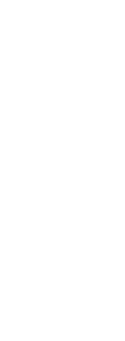

3

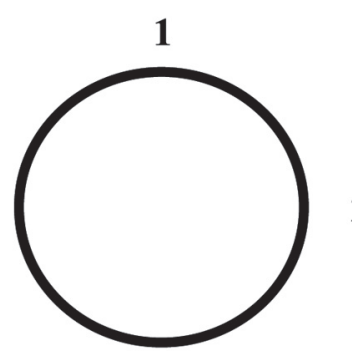

$\mathrm{R}$

\section{Cranial}

Figure 2. Pressure algometry locations at each horn bud. $\mathrm{L}=$ left; $\mathrm{R}=$ right.

disbudding ( $\mathrm{d}-1$ ), and $7 \mathrm{~d}$ following disbudding ( 7). Average daily gains were calculated by dividing the total weight gained between measurements and then dividing by the number of days.

\section{Statistical Analysis}

Analyses were performed in SAS 9.3 (SAS Institute, Cary NC) using a linear mixed effects model with repeated measures. Data obtained from response variables including MNT, cortisol, SP, and $\mathrm{PGE}_{2}$ were logtransformed for normality. Baseline values were used as covariates for all variables analyzed. The fixed effects were treatment (firocoxib, placebo), time, and the interaction between treatment and time. The effect of sex was tested in the statistical model and removed to improve the fit of the statistical analysis when no effect was observed $(P>0.1)$. Trial was a random effect and calf was the subject of repeated measures. F-tests were used to test the significance of main effects and interactions. If significant overall differences were identified among levels of a factor, pairwise comparisons were performed using Tukey's t-tests. Additionally, paired $t$-tests were performed to test the differences between response variable baselines as well as LPS-stimulated and unstimulated baseline ex vivo $\mathrm{PGE}_{2}$ concentrations. Statistical significance was designated as a $P$ value $<0.05 ; P$-values ranging between 0.05 and 0.1 were discussed as a tendency to significance.

\section{RESULTS}

No animals required rescue analgesia or were removed throughout the course of the study. There was no effect of sex observed on any measured responses $(P>0.1)$. As such, sex was removed from the statistical analysis.

\section{Cortisol}

Mean cortisol concentrations were not significantly different between treatment groups $(P=0.80)$ (Table $1)$. Both a time effect $(P<0.0001)$ and time $\times$ treatment interaction $(P=0.0076)$ were observed in cortisol concentrations throughout the 96 -h sampling period (Table 1). Initially, cortisol concentrations increased following disbudding, peaking, on average, at approximately 20 min following the hot-iron procedure. Mean cortisol concentrations decreased thereafter. At $50 \mathrm{~min}$ postdisbudding, placebo-treated calves had a significant reduction $(2.2 \mathrm{nmol} / \mathrm{L})$ in cortisol concentrations compared with firocoxib-treated calves $(P=0.012$; Figure 3a). In contrast, at approximately $48 \mathrm{~h}$ postdisbudding, a significant increase in cortisol concentrations was observed in placebo-treated calves compared with firocoxib-treated calves $(22.8 \pm 2.9$ vs. $11.5 \pm 1.7 \mathrm{nmol} / \mathrm{L}$; $P=0.0006$; Figure 3b). Furthermore, the integrated cortisol response calculated as the area under the effect curve tended to be reduced in firocoxib-treated calves $(1,157.0 \pm 179$ vs. $1,610.8 \pm 255$ nmol.h/L; $P=0.093$; Figure 4).

\section{SP}

Mean \pm standard error SP concentrations in firocoxib-treated calves $(22.7 \pm 0.7 \mathrm{pg} / \mathrm{mL})$ were not significantly different compared with calves receiving placebo

Table 1. Summary table of untransformed response variables of firocoxib- and placebo-treated calves postdisbudding

\begin{tabular}{|c|c|c|c|c|c|}
\hline Response & $\begin{array}{c}\text { Firocoxib } \\
(\mathrm{LSM} \pm \mathrm{SE})\end{array}$ & $\begin{array}{l}\text { Placebo } \\
\mathrm{LSM} \pm \mathrm{SE}\end{array}$ & $\begin{array}{l}\text { Treatment } \\
(P \text {-value })\end{array}$ & $\begin{array}{c}\text { Time } \\
(P \text {-value })\end{array}$ & $\begin{array}{c}\text { Time } \times \text { treatment } \\
(P \text {-value })\end{array}$ \\
\hline Cortisol (nmol/L) & $13.1 \pm 0.9$ & $15.1 \pm 1.0$ & 0.80 & $<0.0001$ & 0.0076 \\
\hline Substance P (pg/mL) & $22.7 \pm 0.7$ & $20.8 \pm 0.4$ & 0.61 & 0.42 & 0.66 \\
\hline Heart rate $\left(\mathrm{bpm}^{1}\right)$ & $109.5 \pm 1.7$ & $109.8 \pm 2.2$ & 0.96 & 0.019 & 0.16 \\
\hline $\mathrm{MNT}^{2}(\mathrm{kgf})$ & $1.15 \pm 0.16$ & $0.96 \pm 0.14$ & 0.56 & $<0.0001$ & 0.84 \\
\hline ADG $(\mathrm{kg} / \mathrm{d})$ & $0.5 \pm 0.1$ & $0.5 \pm 0.1$ & 0.61 & NA & NA \\
\hline
\end{tabular}

${ }^{1} \mathrm{bpm}=$ beats per minute.

${ }^{2} \mathrm{MNT}=$ mechanical nociception threshold. 
(a)

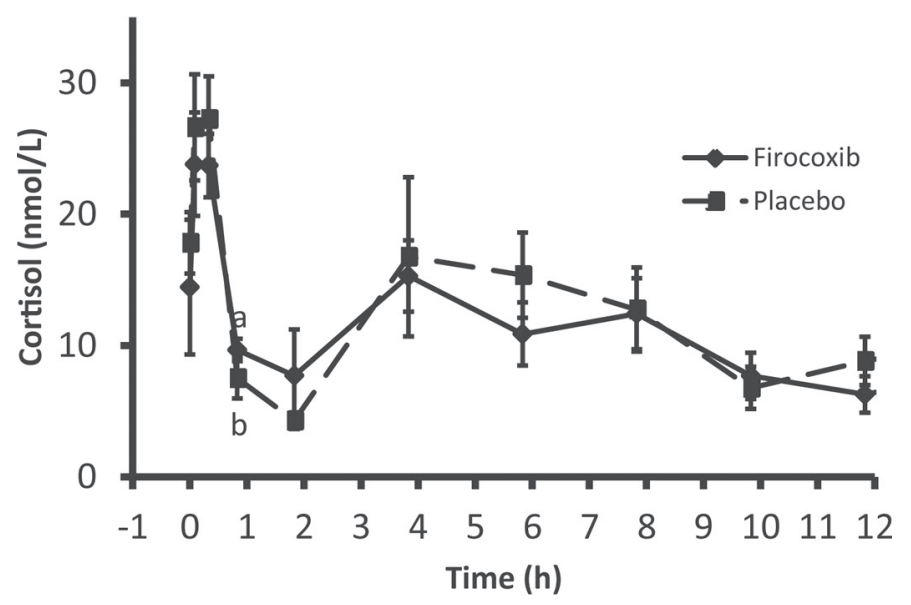

(b)

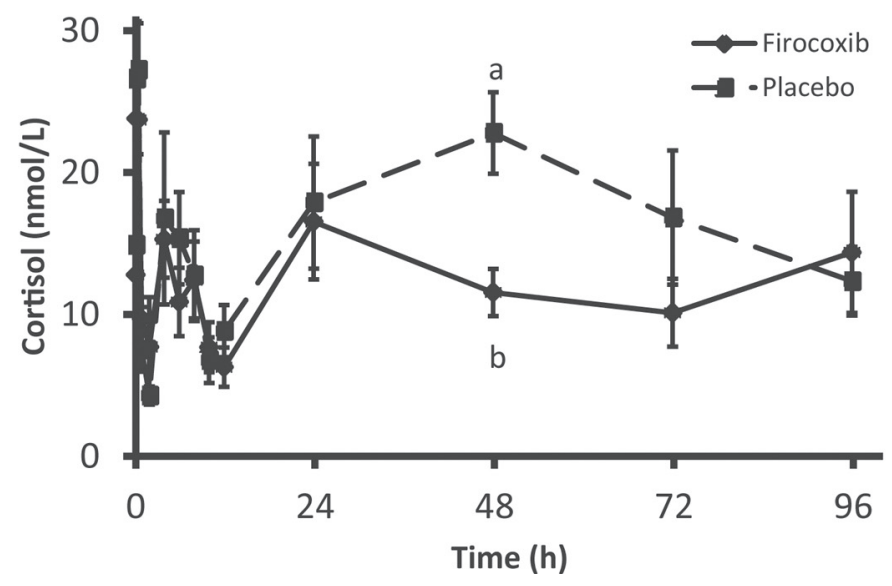

Figure 3. Untransformed cortisol concentrations $( \pm \mathrm{SE})$ over 12 (a) and $96 \mathrm{~h}$ (b) for firocoxib- and placebo-treated calves after cautery disbudding. Baseline values are graphically represented at time 0 , the time of disbudding. Significant differences $(P<0.05)$ between time points are indicated by different letters $(\mathrm{a}, \mathrm{b})$.

$(20.8 \pm 0.4 \mathrm{pg} / \mathrm{mL} ; P=0.61 ;$ Table 1$)$. Additionally, no effect of time $(P=0.42)$ or a time $\times$ treatment interaction $(P=0.66)$ were observed for the 96 -h sampling period.

\section{$\mathrm{PGE}_{2}$}

Due to laboratory error in sample processing, samples collected and processed for ex vivo $\mathrm{PGE}_{2}$ synthesis at 4 and $8 \mathrm{~h}$ were removed from the statistical analysis. An overall treatment effect was observed with $\mathrm{PGE}_{2}$ synthesis reduced in firocoxib-treated calves $(770.4 \pm 97.9$ $\mathrm{pg} / \mathrm{mL})$ compared with placebo treatment $(1,249.7 \pm$ $105.5 \mathrm{pg} / \mathrm{mL} ; P=0.0012)$. Moreover, an effect of time $(P<0.0001)$ and a time $\times$ treatment interaction $(P=$
N Firocoxib Placebo

*

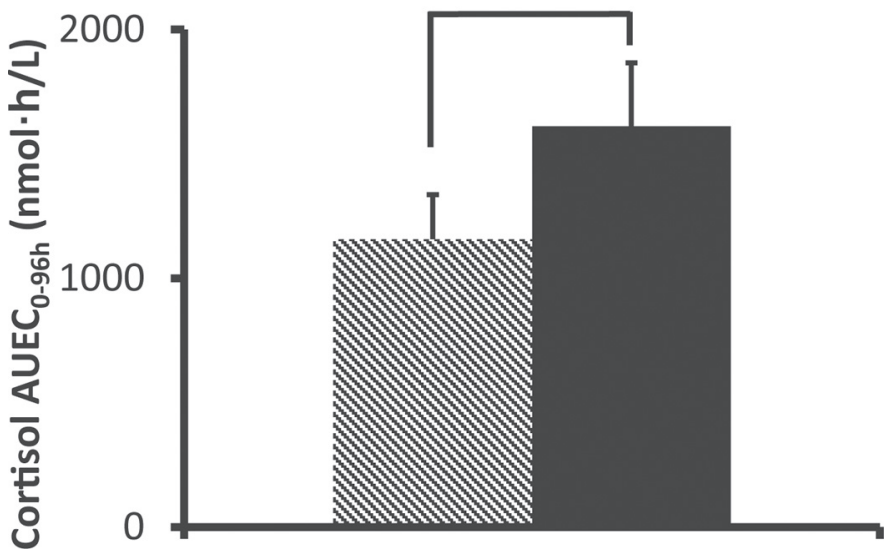

Figure 4. Area under the effect curve (AUEC; \pm SE) of untransformed cortisol concentrations over the 96-h study period for firocoxiband placebo-treated calves postdisbudding. Values were calculated using the linear trapezoid method. An asterisk $\left(^{*}\right)$ indicates differences between treatment groups $(P=0.093)$.

0.019) was observed. Firocoxib treatment resulting in decreased $\mathrm{PGE}_{2}$ concentrations at $12(P<0.0001), 24$ $(P=0.0073)$, and $48 \mathrm{~h}(P=0.0005$; Figure 5$)$. At $72 \mathrm{~h}$, no difference was observed between treatment groups $(P=0.34)$. Baseline LPS-stimulated blood resulted in a significant increase in $\mathrm{PGE}_{2}$ concentrations compared with non-LPS stimulated control samples for both treatment groups $(P<0.0001)$.

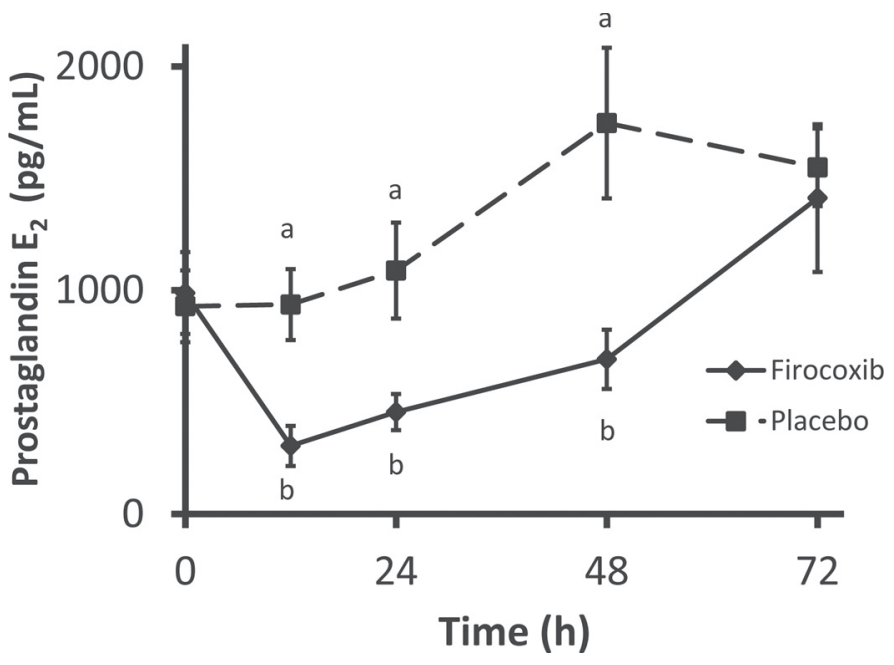

Figure 5. Untransformed ex vivo prostaglandin $\mathrm{E}_{2}$ concentrations $( \pm \mathrm{SE})$ over $72 \mathrm{~h}$ in firocoxib- and placebo-treated calves postdisbudding. Significant differences $(P<0.05)$ between time points are indicated by different letters $(\mathrm{a}, \mathrm{b})$. Baseline values are represented at time 0 . 


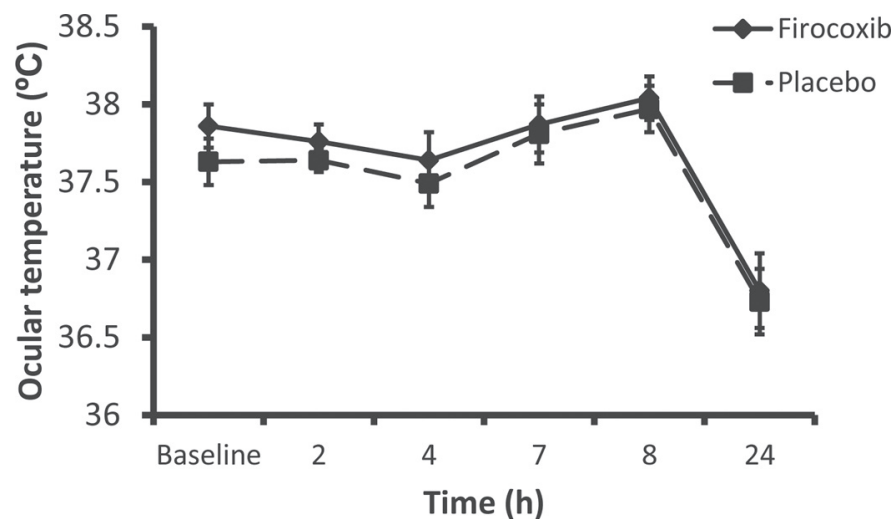

Figure 6. Untransformed ocular temperature $( \pm \mathrm{SE})$ as measured through infrared thermography over $24 \mathrm{~h}$ for firocoxib- and placebotreated calves. Baseline values are indicated.

\section{Infrared Thermography}

Mean OT were not significant between treatment groups $(P=0.85)$. A time effect was observed in OT response following disbudding $(P<0.0001$; Table 1 ; Figure 6). For both firocoxib- and placebo-treated calves, OT numerically decreased $0.12 \pm 0.10^{\circ} \mathrm{C}$ and $0.15 \pm 0.10^{\circ} \mathrm{C}$ from 2 to $4 \mathrm{~h}$ following disbudding. Ocular temperature significantly increased thereafter, with a mean peak temperature recorded at $8 \mathrm{~h}$ for both treatment groups. Additionally, a significant temperature reduction was observed $24 \mathrm{~h}$ postdisbudding for both treatment groups in comparison to all previous time points, including baseline $(P<0.0001)$. No interaction between time and treatment $(P=0.98)$ was observed.

\section{$H R$}

No treatment effects were observed between treatment groups $(P=0.96)$. A time effect was observed with HR altered following disbudding $(P=0.019$; Table 1). There was no time $\times$ treatment interaction $(P=0.16)$. Interestingly, HR significantly decreased in firocoxib-treated calves $24 \mathrm{~h}$ postdisbudding compared with both $7(P=0.021)$ and $8 \mathrm{~h}(P=0.0030)$. This response was not observed in placebo-treated calves.

\section{MNT}

Numerically, firocoxib-treated calves tolerated more pressure around the horn bud area $(1.15 \pm 0.16 \mathrm{~kg})$ compared with placebo-treated controls $(0.96 \pm 0.14)$; however, this effect was not significant $(P=0.56$; Table 1). Overall, a time effect on MNT was observed $(P<$ 0.0001). Postdisbudding measurements were reduced below baseline values throughout the 24 -h testing pe-

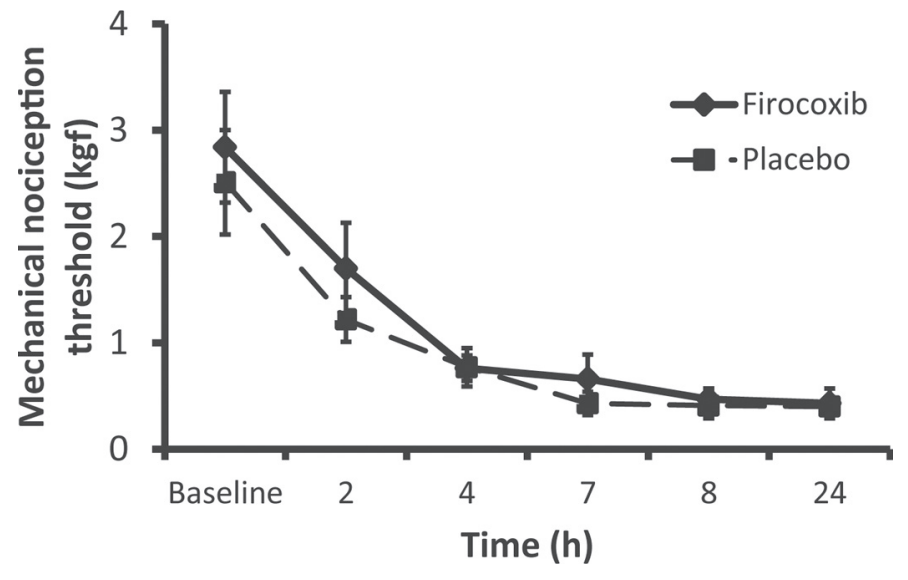

Figure 7. Untransformed mechanical nociception threshold (MNT; $\pm \mathrm{SE}$ ) as measured through pressure algometry over $24 \mathrm{~h}$ for firocoxiband placebo-treated calves. Pressure tolerance did not return to baseline values by the conclusion of MNT measurement. Baseline values are indicated.

riod (Figure 7). There was no evidence of an interaction of time and treatment $(P=0.84)$.

\section{ADG}

Initial weights were determined the day before disbudding. The mean weights (LSM $\pm \mathrm{SE}$ ) before disbudding were $55.5 \pm 1.7$ and $55.0 \pm 2.0 \mathrm{~kg}$ for the firocoxib and placebo groups, respectively. All calves gained weight throughout the study period with final mean weights equaling $59.1 \pm 2.0$ and $59.0 \pm 2.4 \mathrm{~kg}$ for firocoxiband placebo-treated groups, respectively. There was no difference in ADG for firocoxib- and placebo-treated calves $(0.5 \pm 0.1$ vs. $0.5 \pm 0.1 \mathrm{~kg} ; P=0.61$; Table 1$)$.

\section{DISCUSSION}

Cautery disbudding in calves resulted in an increased cortisol concentrations, as well as an increased sensitivity as determined by MNT. Moreover, changes in nociception persisted throughout the 24-h study period where local pressure tolerated by calves did not return to baseline values. Firocoxib administration did not alter the tested responses observed between treatment groups over the initial 24-h period; however, cortisol concentrations between treatment groups diverged at $48 \mathrm{~h}$ postdisbudding, where firocoxib-treated calves had reduced cortisol concentration. Furthermore, the integrated cortisol response tended to be decreased in firocoxib-treated animals compared with calves administered a placebo. These differences observed following the initial $24 \mathrm{~h}$ could be attributed to the administration of an NSAID with persistent concentrations; 
however, additional study is required to determine its long-term effects.

Historically, perioperative analgesics administered to calves before dehorning or disbudding have used NSAID that have data, both public and proprietary, to support an anti-inflammatory claim (Stilwell et al. 2009; Duffield et al., 2010; Heinrich et al., 2010; Glynn et al. 2013). This aids in the dose determination for an investigation into its analgesic potential. However, for our study, no information was publicly available concerning the analgesic use of firocoxib in preweaned calves. As such, the dose of $0.5 \mathrm{mg} / \mathrm{kg}$ used in our study was based on pharmacokinetic information available in the horse labeled for use at $0.1 \mathrm{mg} / \mathrm{kg}$. The equineapproved dose demonstrated analgesia in naturally occurring lameness following multiple daily doses (Orsini et al., 2012). More recently, it has been suggested to use a loading dose in horses to achieve steady state drug concentrations more quickly (Cox et al., 2013). As a result, effective concentrations may be reached more rapidly. In our study, a one-time dose administration was anticipated for the practical application of this analgesic in calves. As such, the increased dose compared with the horse was chosen to best provide potentially effective concentration of drug as well as remain practical in its administration. However, we cannot rule out that differences in pharmacokinetic properties of firocoxib between species may also have contributed to the differences in analgesic response.

A primary property of most NSAID is reducing eicosanoid production via inhibition of cyclooxygenase isoenzymes. Therefore, a potential method of dose evaluation involves an investigation into a drug's ability to decrease $\mathrm{PGE}_{2}$ concentrations, a major eicosanoid metabolite associated with inflammation and nociception threshold reduction (Basbaum et al., 2009). An investigation of the $\mathrm{PGE}_{2}$ in our study indicated the administered dose reduced ex vivo $\mathrm{PGE}_{2}$ synthesis from 12 to $48 \mathrm{~h}$ compared with placebo-treated controls. Although further evaluation is required to determine concentrations necessary to achieve analgesia, it should be noted that the administration of firocoxib at the study dose attained concentrations necessary to significantly inhibit ex vivo $\mathrm{PGE}_{2}$ concentrations for at least $2 \mathrm{~d}$. This is similar to the findings of Allen et al. (2013), who observed a suppression of ex vivo $\mathrm{PGE}_{2}$ synthesis for $48 \mathrm{~h}$ after oral administration of meloxicam at 1 $\mathrm{mg} / \mathrm{kg}$ at the time of disbudding.

During the first $24 \mathrm{~h}$, cortisol concentrations were similar over time for both treatment groups. Although placebo-treated calves had decreased cortisol concentrations $50 \mathrm{~min}$ postdisbudding, the effect size was small and the response may be confounded with the desensitization of the local anesthetic. The initial increase in cortisol concentrations peaking at $20 \mathrm{~min}$ postdisbudding and returning to pretreatment levels within approximately $1 \mathrm{~h}$ is similar to that presented in previous literature (Stafford and Mellor, 2005). Moreover, in combination with a local anesthetic, the use of cautery following amputation dehorning nearly eliminated the cortisol response for 24 (Sutherland et al., 2002) to $36 \mathrm{~h}$ (Sylvester et al., 1998) after dehorning. It should be noted that in the former study, both lidocaine and then bupivacaine $2 \mathrm{~h}$ later were used to provide local anesthesia for a duration of $5 \mathrm{~h}$ (Sutherland et al., 2002). This significantly reduced cortisol response has also been observed in lambs undergoing cautery tail docking, suggesting that cautery may attenuate the nociception signal below the pain threshold for transmission (Lester et al., 1991; Stafford and Mellor, 2011). An attenuation of this systemic response using cautery may contradict the MNT profile observed in our study; however, the pressure algometer evaluates local sensitivity surrounding the horn bud and may not reflect a systemic distress response.

After $24 \mathrm{~h}$, the mean cortisol response diverges between the 2 treatment groups with placebo-treated calves increasing in cortisol with a peak at approximately $48 \mathrm{~h}$ postdisbudding. Using cortisol as a measure of distress, firocoxib administration may have mitigated the distress associated with disbudding. This statement is further supported with evidence suggesting that firocoxib concentrations between 24 and $48 \mathrm{~h}$ continued to reduce ex vivo $\mathrm{PGE}_{2}$ synthesis. Prolonged changes in cortisol associated with dehorning and disbudding have been difficult to routinely characterize. Morisse et al. (1995) reported elevated cortisol concentrations 24 h postdehorning compared with control calves $8 \mathrm{wk}$ of age. More recently, in 8- to 10-wk-old calves, Allen et al. (2013) reported a mean increased cortisol concentration from 96 to $120 \mathrm{~h}$ in calves treated with meloxicam $12 \mathrm{~h}$ before dehorning. Calf behavior, including ear flicks, grazing time, and rumination responses, provide further support that disbudding and dehorning pain may continue for 24 to $48 \mathrm{~h}$ (Faulkner and Weary, 2000; Stafford and Mellor, 2005; Heinrich et al., 2010). These changes in cortisol and behavior may be mediated by an increased inflammatory response evidenced by an increased haptoglobin concentration reported 24 to 48 $\mathrm{h}$ following amputation dehorning in 6-mo-old calves (Glynn et al., 2013). In contrast, other studies report cortisol concentrations return to and are maintained at baseline values 24 (Sutherland et al., 2002) to 36 h (Sylvester et al., 1998) in 3- to 4- or 5- to 6-mo-old calves, respectively, that were scoop dehorned followed by wound cauterization.

Substance P, a neuropeptide previously indicated as a pain biomarker in cattle, was not different between 
treatment groups (Coetzee et al., 2008). Moreover, no significant change in SP over time was noted. These data differ from other investigations evaluating SP following dehorning. In 8- to 10-wk-old calves, Allen et al. (2013) reported a time by treatment interaction with a significant increase in SP concentrations at $120 \mathrm{~h}$ after cautery dehorning in control animals compared with those receiving meloxicam. Furthermore, Coetzee et al. (2012) reported a significant reduction in SP following administration of an NSAID, meloxicam, following scoop dehorning in 4- to 5-mo-old calves. Differences in the length of sample collection time, disbudding or dehorning method, and analytical method used to measure SP may be the reason for the observed disagreement with the present study. Moreover, age differences in these study populations may significantly influence SP response. Dockweiler et al. (2013) reported a decreased response in SP in cattle castrated at $\leq 8 \mathrm{wk}$ in comparison to cattle $\geq 6 \mathrm{mo}$; the authors suggest a reduced pain response or different physiological parameters contributing to this difference. Coupled with data collected in the present study, SP may be a poor indicator of pain in young animals. Both in our study and demonstrated by Allen et al. (2013), no significant differences in SP were reported for the first $96 \mathrm{~h}$ following dehorning. As SP release is thought to be associated with pain, evidence from our study support the hypothesis that cautery may destroy nearby nociceptors necessary to reach pain thresholds needed for central hyperalgesia transmission (Sylvester et al., 1998; Sutherland et al., 2002). It should be noted this hypothesis was derived from the evaluation of the cortisol response following local anesthesia and scoop then cautery dehorned calves greater than 3 mo of age.

Local nociception changes persisted for $24 \mathrm{~h}$ in both treatment groups as observed in the MNT profiles such that nociception thresholds did not return to baseline values during the measured response period. This duration of sensitivity appears to be consistent with other reports indicating a prolonged response following dehorning or disbudding based on behavior (Faulkner and Weary, 2000; Heinrich et al., 2010) and on nociceptive thresholds (Tapper et al., 2011). Average MNT profiles were similar between treatment groups, suggesting firocoxib did not significantly demonstrate antinociceptive effects over the 24-h investigation period postdisbudding. This response differs from MNT values reported following perioperative administration of meloxicam (Heinrich et al., 2010) and ethanol as a local anesthetic (Tapper et al., 2011). Repeated handling for data collection may have heightened the avoidance responses of calves in the current study when compared with the nociception threshold testing performed at one time point by Heinrich and colleagues (2010). Reduction in subtle dehorning pain-related behaviors, such as ear flicking and head rubbing, have been associated with perioperative administration of meloxicam (Heinrich et al., 2010), ketoprofen (Faulkner and Weary, 2000; Duffield et al., 2010), and carprofen (Stilwell et al., 2012), but this was not assessed in the current study.

Changes to the autonomic nervous system response, including HR and OT, were observed after disbudding. Although not statistically significant, the decrease in ocular temperature observed between 2 and $4 \mathrm{~h}$ most likely was due to the loss of the local anesthetic effect, as previously described by Stewart et al. (2009). The significant decrease of ocular temperature at $24 \mathrm{~h}$ for both treatment groups may also suggest a continued autonomic nervous system response caused by disbudding; however, changes in temperatures due to diurnal core temperature changes or environment cannot be eliminated (Vickers et al., 2010; Church et al., 2014). Although prior studies have indicated a reduced volatility of the autonomic nervous system with the use of an NSAID following cautery disbudding or dehorning (Stewart et al., 2009; Heinrich et al., 2009; Coetzee et al., 2012), no treatment differences were observed over the 24-h sampling period for both OT and HR in the present study. Animals were frequently handled before disbudding to help reduce response variations associated with sample collection. However, responses of the autonomic nervous system may vary according to novel stimuli and exertion; frequent handling required for blood collection may result in elevated responses regardless of the administration of an analgesic. As no analgesic effects were noted in any response variable during the first $24 \mathrm{~h}$, firocoxib administration at the study dose may be ineffective at managing the acute nociception and distress associated with cautery disbudding.

\section{CONCLUSIONS}

Evidence provided in the current study indicates cautery disbudding resulted in changes in nociception and cortisol concentrations. The study dose of firocoxib was sufficient to effectively reduce ex vivo $\mathrm{PGE}_{2}$ synthesis; however, determination of analgesic concentrations require further investigation, as no significant differences in analgesic response variables were observed in the first $24 \mathrm{~h}$. As such, the relationship between response variables and ex vivo $\mathrm{PGE}_{2}$ inhibition requires further exploration. Overall, a one-time oral administration of firocoxib reduced cortisol concentrations at $48 \mathrm{~h}$ and contributed to the attenuated integrated concentration of plasma cortisol; however, the acute response $(<24 \mathrm{~h})$ as measured by OT, HR, MNT, cortisol, and SP was unaffected by treatment. Further research is needed 
to determine the significance of the prolonged cortisol response following disbudding and the potential for firocoxib to ameliorate this effect.

\section{ACKNOWLEDGMENTS}

Supported by the Pharmacology Analytical Support Team (PhAST) in the College of Veterinary Medicine at Iowa State University. The authors thank the following individuals who provided invaluable support to the project: Larry Wulf, Jay Lawrence, Jackie Peterson, Travis Vlietstra, Ben Schmidt, Jessie Juarez, Chris Sievers, and Josh Ydstie.

\section{REFERENCES}

Allen, K. A., J. F. Coetzee, L. N. Edwards-Callaway, H. Glynn, J. Dockweiler, B. KuKanich, H. Lin, C. Wang, E. Fraccaro, M. Jones, and L. Bergamasco. 2013. The effect of timing of oral meloxicam administration on physiological responses in calves after cautery dehorning with local anesthesia. J. Dairy Sci. 96:5194-5205.

American Veterinary Medical Association (AVMA). 2012. AVMA Policy: Castration and Dehorning of Cattle. Accessed Jan. 29, 2015. https://www.avma.org/KB/Policies/Pages/Castration-andDehorning-of-Cattle.aspx.

Basbaum, A. I., D. M. Bautista, G. Scherrer, and D. Julius. 2009. Cellular and molecular mechanisms of pain. Cell 139:267-284.

Church, J. S., P. R. Hegadoren, M. J. Paetkau, C. C. Miller, G. RegevShoshani, A. L. Schaefer, and K. S. Schwartzkopf-Genswein. 2014. Influence of environmental factors on infrared eye temperature measurements in cattle. Res. Vet. Sci. 96:220-226. http://dx.doi. org/10.1016/j.rvsc.2013.11.006.

Coetzee, J. F. 2011. A review of pain assessment techniques and pharmacological approaches to pain relief after bovine castration: Practical implications for cattle production within the United States. Appl. Anim. Behav. Sci. 135:192-213.

Coetzee, J. F. 2013. A review of analgesic compounds that can be used in food animals in the United States. Vet. Clin. North Am. Food Anim. Pract. 29:11-28. http://dx.doi.org/10.1016/j. cvfa.2012.11.008.

Coetzee, J. F., B. V. Lubbers, S. E. Toerber, R. Gehring, D. U. Thomson, B. J. White, and M. D. Apley. 2008. Plasma concentrations of substance $\mathrm{P}$ and cortisol in beef calves after castration or simulated castration. Am. J. Vet. Res. 69:751-762. http://dx.doi. org/10.2460/ajvr.69.6.751.

Coetzee, J. F., R. A. Mosher, B. KuKanich, R. Gehring, B. Robert, J. B. Reinbold, and B. J. White. 2012. Pharmacokinetics and effect of intravenous meloxicam in weaned Holstein calves following scoop dehorning without local anesthesia. BMC Vet. Res. 8:153. http://dx.doi.org/10.1186/1746-6148-8-153.

Cox, S., N. Villarino, C. Sommardahl, V. Kvaternick, C. Zarabadipour, L. Siger, J. Yarbrough, A. Amicucci, K. Reed, D. Breeding, and T. Doherty. 2013. Disposition of firocoxib in equine plasma after an oral loading dose and a multiple dose regimen. Vet. J. 198:382-385. http://dx.doi.org/10.1016/j.tvjl.2013.07.035.

Dockweiler, J. C., J. F. Coetzee, L. N. Edwards-Callaway, N. M. Bello, H. D. Glynn, K. A. Allen, M. E. Theurer, M. L. Jones, K. A Miller, and L. Bergamasco. 2013. Effect of castration method on neurohormonal and electroencephalographic stress indicators in Holstein calves of different ages. J. Dairy Sci. 96:4340-4354. http://dx.doi.org/10.3168/jds.2012-6274.

Doherty, T. J., H. G. Kattesh, R. J. Adcock, M. G. Welborn, A. M. Saxton, J. L. Morrow, and J. W. Dailey. 2007. Effects of a concentrated lidocaine solution on the acute phase stress response to dehorning in dairy calves. J. Dairy Sci. 90:4232-4239.
Donalisio, C., R. Barbero, B. Cuniberti, C. Vercelli, M. Casalone, and G. Re. 2013. Effects of flunixin meglumine and ketoprofen on mediator production in ex vivo and in vitro models of inflammation in healthy dairy cows. J. Vet. Pharmacol. Ther. 36:130-139.

Duffield, T. F., A. Heinrich, S. T. Millman, A. DeHaan, S. James, and K. Lissemore. 2010. Reduction in pain response by combined use of local lidocaine anesthesia and systemic ketoprofen in dairy calves dehorned by heat cauterization. Can. Vet. J. 51:283-288.

Faulkner, P. M., and D. M. Weary. 2000. Reducing pain after dehorning in dairy calves. J. Dairy Sci. 83:2037-2041.

Fraccaro, E., J. F. Coetzee, R. Odore, L. N. Edwards-Callaway, B. Kukanich, P. Badino, L. Bertolotti, H. Glynn, J. Dockweiler, K. Allen, and L. Bergamasco. 2013. A study to compare circulating flunixin, meloxicam and gabapentin concentrations with prostaglandin $\mathrm{E}_{2}$ levels in calves undergoing dehorning. Res. Vet. Sci 95:204-211. http://dx.doi.org/10.1016/j.rvsc.2013.01.018.

Glynn, H. D., J. F. Coetzee, L. N. Edwards-Callaway, J. C. Dockweiler, K. A. Allen, B. Lubbers, M. Jones, E. Fraccaro, L. L. Bergamasco, and B. KuKanich. 2013. The pharmacokinetics and effects of meloxicam, gabapentin, and flunixin in postweaning dairy calves following dehorning with local anesthesia. J. Vet. Pharmacol. Ther. 36:550-561. http://dx.doi.org/10.1111/jvp.12042.

Heinrich, A., T. F. Duffield, K. D. Lissemore, and S. T. Millman. 2010. The effect of meloxicam on behavior and pain sensitivity of dairy calves following cautery dehorning with a local anesthetic. J. Dairy Sci. 93:2450-2457.

Heinrich, A., T. F. Duffield, K. D. Lissemore, E. J. Squires, and S. T. Millman. 2009. The impact of meloxicam on postsurgical stress associated with cautery dehorning. J. Dairy Sci. 92:540-547.

Huber, J., T. Arnholdt, E. Möstl, C. C. Gelfert, and M. Drillich. 2013 Pain management with flunixin meglumine at dehorning of calves. J. Dairy Sci. 96:132-140.

Lester, S. J., D. J. Mellor, R. N. Ward, and R. J. Holmes. 1991. Cortisol response of young lambs to castration and tailing using different methods. N. Z. Vet. J. 39:134-138.

McCann, M. E., D. R. Andersen, D. Zhang, C. Brideau, W. C. Black, P. D. Hanson, and G. J. Hickey. 2004. In vitro effects and in vivo efficacy of a novel cyclooxygenase-2 inhibitor in dogs with experimentally induced synovitis. Am. J. Vet. Res. 65:503-512.

McCann, M. E., D. R. Anderson, C. Brideau, W. C. Black, D.-H. Zhang, and G. J. Hickey. 2002 In vitro activity and in vivo efficacy of a novel CQX-2 inhibitor in the horse. Page 789 in Proc. Acad. Vet. Intern. Med., Dallas, TX.

McMeekan, C. M., K. J. Stafford, D. J. Mellor, R. A. Bruce, R. N. Ward, and N. G. Gregory. 1998. Effects of regional analgesia and/ or a non-steroidal anti-inflammatory analgesic on the acute cortisol response to dehorning in calves. Res. Vet. Sci. 64:147-150.

Molony, V., and J. E. Kent. 1997. Assessment of acute pain in farm animals using behavioral and physiological measurements. J. Anim. Sci. $75: 266-272$

Morisse, J. P., J. P. Cotte, and D. Huonnic. 1995. Effect of dehorning on behavior and plasma cortisol responses in young calves. Appl. Anim. Behav. Sci. 43:239-247.

Orsini, J. A., W. G. Ryan, D. S. Carithers, and R. C. Boston. 2012 Evaluation of oral administration of firocoxib for the management of musculoskeletal pain and lameness associated with osteoarthritis in horses. Am. J. Vet. Res. 73:664-671. http://dx.doi. org/10.2460/ajvr.73.5.664.

Rialland, P., C. Otis, M. L. de Courval, P. Y. Mulon, D. Harvey, S. Bichot, D. Gauvin, A. Livingston, F. Beaudry, P. Hélie, D. Frank J. R. Del Castillo, and E. Troncy. 2014. Assessing experimental visceral pain in dairy cattle: A pilot, prospective, blinded, randomized, and controlled study focusing on spinal pain proteomics. J. Dairy Sci. 97:2118-2134. http://dx.doi.org/10.3168/jds.20137142 .

Stafford, K. J., and D. J. Mellor. 2005. Dehorning and disbudding distress and its alleviation in calves. Vet. J. 169:337-349.

Stafford, K. J., and D. J. Mellor. 2011. Addressing the pain associated with disbudding and dehorning in cattle. Appl. Anim. Behav. Sci. $135: 226-231$. 
Stewart, M., K. J. Stafford, S. K. Dowling, A. L. Schaefer, and J. R. Wester. 2008. Eye temperature and heart rate variability of calves disbudded with or without local anesthetic. Physiol. Behav. 93:789-797.

Stewart, M., J. M. Stookey, K. J. Stafford, C. B. Tucker, A. R. Rogers, S. K. Dowling, G. A. Verkerk, A. L. Schaefer, and J. R. Webster. 2009. Effects of local anesthetic and a nonsteroidal antiinflammatory drug on pain responses of dairy calves to hot-iron dehorning. J. Dairy Sci. 92:1512-1519.

Stilwell, G., R. C. de Carvalho, M. S. Lima, and D. M. Broom. 2009. Effect of caustic paste disbudding, using local anaesthesia with and without analgesia, on behavior and cortisol of calves. Appl. Anim. Behav. Sci. 116:35-44.

Stilwell, G., M. S. Lima, and D. M. Broom. 2008. Comparing plasma cortisol and behaviour of calves dehorned with caustic paste after non-steroidal-anti-inflammatory analgesia. Livest. Sci. 119:63-69.

Stilwell, G., M. S. Lima, R. C. Carvalho, and D. M. Broom. 2012. Effects of hot-iron disbudding using regional anesthesia with and without carprofen, on cortisol and behavior of calves. Res. Vet. Sci. $92: 338-341$.

Stock, M. L., S. L. Baldridge, D. D. Griffin, and J. F. Coetzee. 2013. Bovine dehorning: Assessing pain and providing analgesic management. Vet. Clin. North Am. Food Anim. Pract. 29:103-133.

Stock, M. L., R. Gehring, L. A. Barth, L. W. Wulf, and J. F. Coetzee. 2014. Pharmacokinetics of firocoxib in preweaned calves after oral and intravenous administration. J. Vet. Pharmacol. Ther. http:// dx.doi.org/10.1111/jvp.12124
Sutherland, M. A., D. J. Mellor, K. J. Stafford, N. G. Gregory, R. A. Bruce, and R. N. Ward. 2002. Effect of local anesthetic combined with wound cauterization on the cortisol response to dehorning in calves. Aust. Vet. J. 80:165-167.

Sylvester, S. P., D. J. Mellor, K. J. Stafford, R. A. Bruce, and R. N. Ward. 1998. Acute cortisol responses of calves to scoop dehorning using local anaesthesia and/or cautery of the wound. Aust. Vet. J. $76: 118-122$.

Tapper, K. R., J. P. Goff, B. L. Leuschen, J. K. West, and S. T. Millman. 2011. Novel techniques for anesthesia during disbudding of calves. J. Anim. Sci. 89(E-Suppl.):413. (Abstr.).

USDA. 2010. Dairy 2007: Heifer Calf Health and Management Practices on U.S. Dairy Operations, 2007. USDA:APHIS:VS-CEAH. National Health Monitoring System, Ft. Collins, CO.

Van Engen, N. K., M. L. Stock, T. Engelken, R. C. Vann, L. W. Wulf, L. A. Karriker, W. D. Busby, J. Lakritz, A. J. Carpenter, B. J. Bradford, W. H. Hsu, C. Wang, and J. F. Coetzee. 2014 Impact of oral meloxicam on circulating physiological biomarkers of stress and inflammation in beef steers after long-distance transportation. J. Anim. Sci. 92:498-510. http://dx.doi.org/10.2527/ jas.2013-6857.

Vickers, L. A., O. Burfeind, M. A. von Keyserlingk, D. M. Veira, D. M. Weary, and W. Heuwieser. 2010. Technical note: Comparison of rectal and vaginal temperatures in lactating dairy cows. J. Dairy Sci. 93:5246-5251. http://dx.doi.org/10.3168/jds.2010-3388. 